\title{
Periostin is up-regulated in high grade and high stage prostate cancer
}

\author{
Verena Tischler ${ }^{1}$, Florian R Fritzsche1, Peter J Wild ${ }^{1}$, Carsten Stephan ${ }^{3}$, Hans-Helge Seifert², Marc-Oliver Riener ${ }^{1}$, \\ Thomas Hermanns², Ashkan Mortezavi2, Josefine Gerhardt1, Peter Schraml1, Klaus Jung3,4, Holger Moch1, \\ Alex Soltermann ${ }^{+1}$ and Glen Kristiansen ${ }^{*+1}$
}

\begin{abstract}
Background: Expression of periostin is an indicator of epithelial-mesenchymal transition in cancer but a detailed analysis of periostin expression in prostate cancer has not been conducted so far.

Methods: Here, we evaluated periostin expression in prostate cancer cells and peritumoural stroma immunohistochemically in two independent prostate cancer cohorts, including a training cohort $(n=93)$ and a test cohort $(n=325)$. Metastatic prostate cancers $(n=20)$, hormone refractory prostate cancers $(n=19)$ and benign prostatic tissues $(n=38)$ were also analyzed.

Results: In total, strong epithelial periostin expression was detectable in 142 of 418 (34.0\%) of prostate carcinomas and in 11 of 38 benign prostate glands (28.9\%). Increased periostin expression in carcinoma cells was significantly associated with high Gleason score $(p<0.01)$ and advanced tumour stage $(p<0.05)$ in the test cohort. Whereas periostin expression was weak or absent in the stroma around normal prostate glands, strong periostin expression in tumour stroma was found in most primary and metastatic prostate cancers. High stromal periostin expression was associated with higher Gleason scores $(p<0.001)$. There was a relationship between stromal periostin expression and shortened PSA relapse free survival times in the training cohort $(p<0.05)$.
\end{abstract}

Conclusions: Our data indicate that periostin up-regulation is related to increased tumour aggressiveness in prostate cancer and might be a promising target for therapeutical interventions in primary and metastatic prostate cancer.

\section{Background}

Periostin (POSTN) is a $93 \mathrm{kDa} \mathrm{N}$-glycoprotein, first described in 1993 in mouse osteoblasts as osteoblast-specific factor 2 (OSF-2). It shows homology with the cell adhesion molecules fasciclin 1 (drosophila) and betaIgH3 (human), sharing features that are thought to explain some of its functional characteristics [1,2] like involvement in cell adhesion and osteoblast recruitment [3].

Periostin has been found in several, mainly collagenrich and fetal tissues as an extracellular matrix protein and is up-regulated by mechanical stress during tissue repair and (re)generation [4-8]. Periostin expression can be induced by vascular injury which in turn induces vas-

\footnotetext{
*Correspondence: glen.kristiansen@usz.ch

1 Institute for Surgical Pathology, University Hospital Zurich, Zurich, Switzerland + Contributed equally

Full list of author information is available at the end of the article
}

cular endothelial growth factor receptor 2 with consequent promotion of angiogenesis $[9,10]$. After myocardial infarction, periostin up-regulation seems to be important for the healing process $[11,12]$.

As a ligand to alpha(V)beta(3) and alpha(V)beta(5) integrin periostin appears to activate the Akt/PKB (protein kinase B) pathway, known to facilitate cell survival and tumourigenesis [13-15].

High expression of periostin protein or mRNA was detected in most solid tumours including breast, colon, head and neck, pancreatic, papillary thyroid, ovarian, lung, gastric and liver carcinoma, as well as neuroblastoma $[9,13,16-33]$. As periostin is a secreted protein, it is not surprising that elevated periostin levels in serum and pleural effusion have recently been detected in lung cancer patients $[28,34]$. Suggested effects of periostin on tumour cells include increased growth and resistance against hypoxia and chemotherapeutics $[16,17]$. 
So far there is only a single report on periostin expression in prostate cancer [35]. Increased cancer cell expression of periostin compared to normal glands was found during early stages of prostate cancer whereas in advanced stages stromal periostin expression prevailed [35]. The aim of our study was to determine the periostin expression in the stromal and epithelial compartment of the tumour, as well as the correlation with clinical data including patient follow up data in a larger cohort.

\section{Methods}

\section{Patients}

A training cohort was used for the establishment of a periostin evaluation algorithm. The training cohort consisted of tissue of 93 prostate cancer patients diagnosed between 1990 and 2001 at the Institute of Pathology, Charité - Universitätsmedizin Berlin. In this cohort cases with and without PSA relapse were selectively chosen to study the relevance of biomarkers for prediction of PSA relapse. The median age was 61 years (range $47-73$ years). The pT-status was pT2 in $42(45.2 \%)$ and pT3/4 in 51 (54.8\%) cases. The Gleason score was $<7$ in 23 (24.7\%), 7 in $39(41.9 \%)$ and $>7$ in $31(33.3 \%)$ cases. Forty-one (44.1\%) tumours were judged R1, 50 (53.8\%) R0 and 2 (2.1\%) Rx. Forty-three (46.2\%) patients had a PSA relapse. The median follow-up time was 45 months (range 3-180 months).

In a second step, periostin expression was analyzed in a larger test cohort with 325 primary prostate cancers. The test cohort consisted of 325 consecutive patients treated with prostatectomy for prostate cancer between 1993 and 2006 at the Department of Urology, University Hospital Zurich. The median age was 64 years (range $46-79$ years). The pT-status was pT2 in $205(63.1 \%)$ and pT3/4 in 120 (36.9\%) cases. The Gleason score was $<7$ in 50 (15.4\%), 7 in 194 (59.7\%) and $>7$ in 81 (24.9\%) tumours. Concerning surgical margins, $112(34.5 \%)$ tumours were R1, 207 (63.7\%) R0 and 6 (1.8\%) Rx. Sixty-eight (20.9\%) patients had a PSA relapse. The median follow-up time was 72 months (range 0-163 months). Data on relapse free survival times was available for 211 of the patients. In addition 20 metastatic prostate cancers (organ metastasis; 19 bone metastasis and 1 bladder metastasis), 19 hormone resistant prostate cancers and 38 cases of benign prostatic tissue were evaluated. The 19 hormone resistant prostate cancer specimens were from patients undergoing palliative transurethral prostate resection in advanced disease.

The study was approved by the the Charite University Ethics Committee (EA1/06/2004) and by the Cantonal Ethics Committee of Zurich (StV 25-2007 neu). In the latter, necessity of patients' informed consent was explicitely ruled out, since this is a retrospective study.

\section{Tissue microarray construction}

The tissue microarrays (TMA) were constructed as previously described [36]. We used commercially available tissue arrayers (Beecher Instruments, Woodland, CA, USA) and applied a core diameter of $0.6 \mathrm{~mm}$ for the tissue samples of Zurich and $1.0 \mathrm{~mm}$ for the tissue samples of Berlin. Each tumour was represented by one tissue core.

\section{Immunohistochemistry (IHC)}

The TMA blocks were freshly cut $(3 \mu \mathrm{m})$ and mounted on superfrost slides (Menzel Gläser, Braunschweig, Germany). IHC was conducted with the Ventana Benchmark automated staining system (Ventana Medical Systems, Tucson, AZ, USA) using Ventana reagents and a polyclonal antibody against human periostin (OSF-2/periostin, BioVendor Laboratory Medicine, Modrice, Czech Republic; RD181045050 RD-932, 1:500) after standard $(\mathrm{CC} 1 \mathrm{~m})$ heat induced antigen retrieval as described before [32]. The antibody dilution was titrated using small test arrays as described elsewhere [32]. Detection was performed using the UltraVIEW ${ }^{m m}$ DAB detection kit.

\section{Evaluation of stainings}

The periostin protein expression was evaluated by two clinical pathologists (FRF, GK) on a multi-headed microscope. The test cohort was subsequently re-evaluated by another pathologist (AS).

For evaluation of epithelial and stromal periostin expression, we implemented an immuno-reactive score including intensity and quantity of cells stained. The staining intensity was scored negative $(0)$, weak $(1+)$, moderate $(2+)$ or strong $(3+)$. The quantity of stained cells was scored zero $(0),<10 \%(1+), 10-50 \%(2+), 51-80 \%$ $(3+)$ or $>80 \%(4+)$. Intensity and quantity were multiplied (immunoreactive score (IRS), range 0-12).

\section{Statistical analysis}

Statistical analyses were performed with SPSS 17.0 (SPSS Inc., Chicago, IL, USA). The median value of the IRS was used as cut-off point to dichotomize the tumours into a "periostin low" and "periostin high" group. Fisher's exact and chi-squared tests were applied to assess associations between categorized periostin expression and clinicopathological parameters. Correlations were computed using Spearman's bivariate rank order correlation. Univariate survival analysis was carried out according to Kaplan-Meier, differences in survival curves were assessed with the Log rank test. P-values $<0.05$ were considered significant.

\section{Results}

Periostin expression in epithelia and stroma of prostate tissues

Distinct stromal and epithelial staining characteristics allowed an absolutely certain evaluation of the periostin 


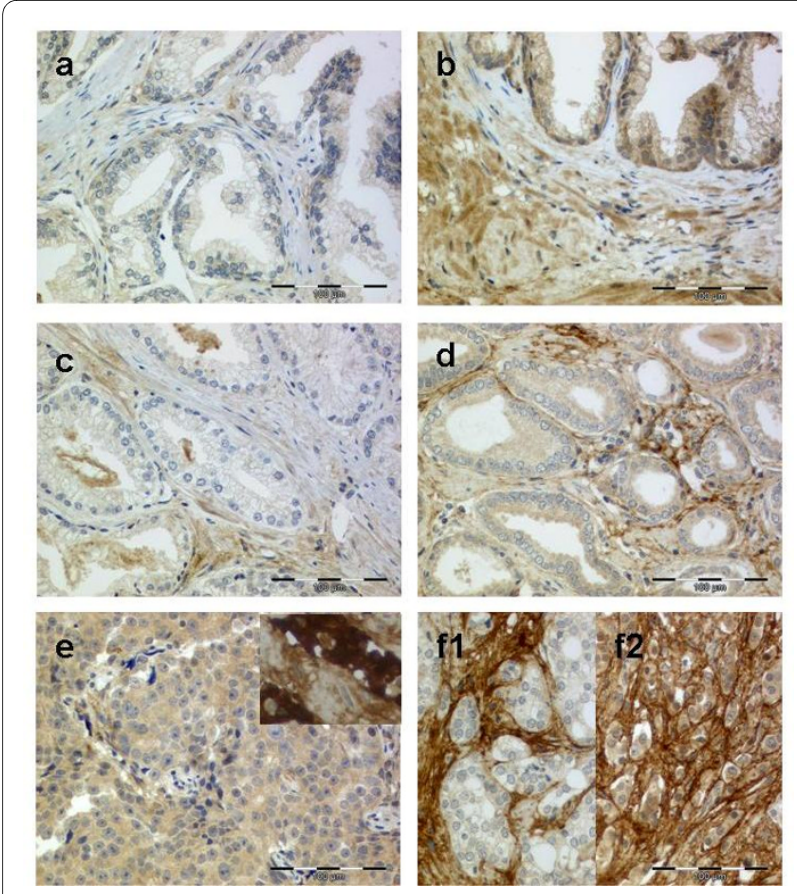

Figure 1 Periostin protein expression in malignant and benign prostate tissue. Weak (a) to moderate (b) epithelial and negative (a) to weak (b) stromal periostin expression in benign prostate glands. In contrast to most cancer cases, in benign tissue with stromal periostin expression the direct periglandular area is rather negative. Some cases showed a weak periostin positivity of basal cells. Prostate cancers with negative (c), weak (d), moderate (e/f2) and strong (e inset) epithelial periostin expression. The peritumoural stroma was weakly (c), moderately $(\mathbf{d})$ or strongly $(\mathbf{f} \mathbf{1} / \mathbf{f} \mathbf{2})$ positive.

staining (Figure 1a and $1 \mathrm{~b}$ ). Benign prostate glands expressed high stromal periostin in only $2 / 38$ cases and high epithelial periostin in $11 / 38$ cases. From the 38 benign prostate samples, 24 displayed no periglandular stromal and 14 no epithelial periostin expression. Of the 24 benign cases without stromal periostin expression, 19 showed epithelial periostin expression and vice versa of the 14 benign cases without periostin expression, 9 revealed stromal periostin expression. Both periostin epithelial and stromal negativity occurred in 5 of the benign cases. Five cases were positive for periostin in both epithelia and stroma. Basal cells showed in some cases a slightly stronger staining than the inner secretory cell layer. In the remaining tumour epithelia, periostin was detected in the cytoplasm without luminal or membranous accentuation. Nuclear staining was not observed. The stroma displayed a fibrillary pattern with considerable variation of intensity. Staining intensity differed frequently within a respective case between the stroma and epithelium.

Tumour stroma was positive in all cases of the training cohort and most cases of the test cohort. Only 11 (3.4\%) cases of the test cohort were negative. An IRS above 2 was found in the vast majority of primary $(82.8 \%)$, hormone resistant $(78.9 \%)$ and metastatic $(85 \%)$ tumours. Using our periostin score, it was possible to differentiate between low and high periostin expression levels using the median. The median stromal IRS for both primary prostate cancer cohorts was 6 with a mean value of about 5.5.

Sixty (18.5\%) primary prostate cancer cases showed no epithelial periostin expression and 189 (58.2\%) cases had an IRS equal to or below 3 (median 3). In total, 142/418 prostate cancer cases expressed high levels of epithelial periostin. Only 7.4\% of cases exhibited an IRS for epithelial periostin expression above 6. Revalidation of the stainings resulted in the same median IRS values.

For the 19 hormone resistant prostate cancers the median IRS was 8 for the stromal and 4 for the epithelial periostin expression (means: 6.8 and 5.1). In the $20 \mathrm{sam}$ ples from prostate cancer metastases the mean and median IRS of epithelial and stromal periostin expression did not differ from that in the primary prostate cancers.

\section{Correlations and associations with clinico-pathological parameters}

In the training cohort, stromal periostin expression showed no correlation (Spearman rank order) with any of the clinico-pathological parameters (age, pT-status, Gleason score, residual status). A higher pT stage was significantly associated with high epithelial periostin expression $(\mathrm{p}=0.026$, Table 1). However, Fisher's exact test revealed a significant association of higher periostin stromal expression with positive resection margins (R1) (high periostin expression in $\mathrm{R} 0$ versus $\mathrm{R} 1: 14 \%(\mathrm{n}=7)$ versus $39 \%(\mathrm{n}=16) ; \mathrm{p}=0.008)$. No other associations were detected (Table 1). In the test cohort, high stromal and epithelial periostin expression were both associated with high Gleason scores $(\mathrm{p}=0.011$ and 0.007 , Table 2). For epithelial expression an additional significant association with advanced $\mathrm{pT}$-status was demonstrated $(\mathrm{p}=0.048$, Table 2). In the Spearman rank order correlation for the test cohort, the significant associations from above could be confirmed for epithelial expression (p-values: 0.001 and 0.047 , Table 3). For stromal expression, the correlation with Gleason score was also significant $(\mathrm{p}=0.003$, Table 3). Stromal periostin expression was significantly correlated with epithelial periostin expression $(\mathrm{p}=0.003$, Table 3).

\section{Periostin and PSA relapse free survival}

The standard prognosticators (pT-status, Gleason score and residual tumour) correlated significantly with shortened PSA relapse free survival in both cohorts (Table 4, training cohort not shown). In the training cohort, high 
Table 1: Stromal and epithelial periostin expression in prostate cancer and clinico-pathological parameters of the training cohort

\begin{tabular}{|c|c|c|c|c|c|c|}
\hline & $\begin{array}{c}\text { Total } \mathbf{n} \\
(\%)\end{array}$ & $\begin{array}{l}\text { Periostin stromal } \\
\text { low n (\%) }\end{array}$ & $\begin{array}{l}\text { Periostin stromal } \\
\text { high n (\%) }\end{array}$ & $\begin{array}{l}\text { Periostin epithelial } \\
\text { low n (\%) }\end{array}$ & $\begin{array}{l}\text { Periostin epithelial } \\
\text { high n (\%) }\end{array}$ & $\begin{array}{l}\text { p-values } \\
\text { stromal/ } \\
\text { epithelial }\end{array}$ \\
\hline All cases & $93(100)$ & $45(48.4)$ & $48(51.6)$ & $87(93.5)$ & $6(6.5)$ & \\
\hline \multirow[t]{3}{*}{ Age } & & & & & & $\begin{array}{c}0.905 / \\
0.484\end{array}$ \\
\hline & 49 (52.7) & $24(49.0)$ & $25(51.0)$ & $45(91.8)$ & $4(8.2)$ & \\
\hline & $44(47.3)$ & $21(47.7)$ & $23(52.3)$ & $42(95.5)$ & $2(4.5)$ & \\
\hline \multirow[t]{3}{*}{ pT-status } & & & & & & $0.573 / \mathbf{0 . 0 2 6}$ \\
\hline & $42(45.2)$ & $22(52.4)$ & $20(47.6)$ & $42(100)$ & $0(0)$ & \\
\hline & $51(54.8)$ & $23(45.1)$ & $28(54.9)$ & $43(84.3)$ & $6(11.7)$ & \\
\hline Gleason score & & & & & & $\begin{array}{c}0.523 / \\
0.404\end{array}$ \\
\hline $3-6$ & $23(24.8)$ & $13(56.5)$ & $10(43.5)$ & $22(95.7)$ & $1(4.3)$ & \\
\hline 7 & 39 (41.9) & $19(48.7)$ & $20(51.3)$ & $38(97.4)$ & $1(2.6)$ & \\
\hline $8-10$ & $31(33.3)$ & $13(41.9)$ & $18(58.1)$ & $27(87.1)$ & $4(12.9)$ & \\
\hline Residual tumoura & & & & & & $\begin{array}{l}0.322 / \\
0.052\end{array}$ \\
\hline Ro & $50(54.9)$ & $26(52.0)$ & $24(48.0)$ & $49(98.0)$ & $1(0.02)$ & \\
\hline $\mathrm{R} 1$ & $41(45.1)$ & $17(41.5)$ & $24(58.5)$ & $36(87.8)$ & $5(12.2)$ & \\
\hline
\end{tabular}

aTwo cases were $\mathrm{Rx}$

stromal periostin was significantly associated with shortened PSA relapse free survival times ( $\mathrm{p}<0.05$; Figure $2 \mathrm{a}$ ).

In the test cohort, neither stromal nor epithelial periostin expression reached prognostic significance (relapse free survival, $\mathrm{p}=0.373$ respectively $\mathrm{p}=0.722$ ) (Figure $2 \mathrm{~b}$ ).

\section{Discussion}

In this study, we provide evidence for periostin up-regulation during prostate cancer progression. Periostin expression was found in both epithelial cancer cells and in peritumoural stroma. Recently, our group has demonstrated that periostin as a marker for the epithelial-mesenchymal-transition (EMT) programme in lung cancer is prognostically relevant [32]. EMT is correlated with tumour progression and represents an important form of tumour-stroma interaction facilitating the stromal invasion of the cancer cells. Periostin seems to play an important part in this prognostically adverse transdifferentiation process. However, the regulation mechanisms of periostin in tumour progression have not been elucidated so far. Our data demonstrate a significant association between periostin and pT-stage, Gleason grade and involvement of prognosis in two different prostate cancer cohorts, suggesting that EMT is of utmost importance for prostate cancer progression. There is only one study by Tsunoda et al. observing a prostate cancer patient cohort of 77 prostate cancers showing increased periostin expression in early prostate cancer stages as well as in the stroma of advanced prostate cancer cases [35]. This is in contrast to our study of 418 prostate carcinomas where we find increased epithelial periostin expression positively correlated to grade and stage and increased stromal periostin positively correlated to grade. Augmentation of both epithelial and stromal periostin in our cohort is a characteristic of the advanced and more aggressive prostate cancer cases. This observation is further supported by the finding that only $2 / 38$ benign prostate tissues expressed stromal periostin. The differences of Tsunoda et al. and our results may be explained by the sample number (77 versus 418 ) and differences in grade and stage. Our test cohort was represented by $63.1 \%$ pT2 and $36.9 \%$ pT3/4 tumours whereas Tsunoda's cohort comprised of $18.2 \%$ pT2 and $74.0 \%$ pT3/4 tumours. Grade in our test cohort was < 7 in $15.4 \%, 7$ in $59.7 \%$ and $>7$ in 
Table 2: Stromal and epithelial periostin expression in prostate cancer and clinico-pathological parameters of the test cohort

\begin{tabular}{|c|c|c|c|c|c|c|}
\hline & $\begin{array}{c}\text { Total n } \\
\text { (\%) }\end{array}$ & $\begin{array}{l}\text { Periostin stromal } \\
\quad \text { low n (\%) }\end{array}$ & $\begin{array}{l}\text { Periostin stromal } \\
\text { high n (\%) }\end{array}$ & $\begin{array}{l}\text { Periostin epithelial } \\
\text { low n (\%) }\end{array}$ & $\begin{array}{l}\text { Periostin epithelial } \\
\text { high n (\%) }\end{array}$ & $\begin{array}{c}\text { p-values stromal/ } \\
\text { epithelial }\end{array}$ \\
\hline All cases & $325(100)$ & $224(68.9)$ & $101(31.1)$ & $189(58.2)$ & $136(41.8)$ & \\
\hline \multirow[t]{3}{*}{ Age } & & & & & & $\begin{array}{c}0.120 / \\
1.000\end{array}$ \\
\hline & $165(50.8)$ & $107(64.8)$ & $58(35.2)$ & $96(58.2)$ & $69(41.8)$ & \\
\hline & $160(49.2)$ & $117(73.1)$ & $43(26.9)$ & $93(58.1)$ & $67(41.9)$ & \\
\hline \multirow[t]{3}{*}{ pT-status } & & & & & & $0.710 / \mathbf{0 . 0 4 8}$ \\
\hline & $205(63.1)$ & $143(69.8)$ & $62(30.2)$ & $128(62.4)$ & 77 (37.6) & \\
\hline & $120(36.9)$ & $81(67.5)$ & $39(32.5)$ & $61(50.8)$ & $59(49.2)$ & \\
\hline Gleason score & & & & & & $\begin{array}{l}0.011 / \\
0.007\end{array}$ \\
\hline $3-6$ & $50(15.4)$ & $40(80.0)$ & $10(20.0)$ & $35(70.0)$ & $15(30.0)$ & \\
\hline 7 & $194(59.7)$ & $136(70.1)$ & $58(29.9)$ & $116(59.8)$ & $78(40.2)$ & \\
\hline $8-10$ & $81(24.9)$ & $48(59.3)$ & $33(40.7)$ & $38(46.9)$ & $43(53.1)$ & \\
\hline Residual tumoura & & & & & & $\begin{array}{c}0.451 / \\
0.634\end{array}$ \\
\hline Ro & $207(63.7)$ & $139(67.1)$ & $68(32.9)$ & $119(57.5)$ & $88(42.5)$ & \\
\hline $\mathrm{R} 1$ & $112(34.5)$ & 80 (71.4) & $32(28.6)$ & $68(60.7)$ & $44(39.3)$ & \\
\hline
\end{tabular}

aSix cases were $\mathrm{Rx}$

24.9\%. Tsunoda's cohort had a much higher percentage of Gleason $8-10$ of $55.8 \%$. Altogether, our test cohort might be more representative for early stages of prostate cancer than Tsunoda's which could well explain the observed difference.
We do acknowledge that a core diameter of $0.6 \mathrm{~mm}$ per prostate cancer case might not be fully representative for a given case. This is especially of importance in small cohorts. However, during the preparation of our tissue microarray, we reviewed each case very carefully to choose a representative area of tumour tissue.

Table 3: Periostin protein expression (stromal and epithelial) with clinico-pathological parameters in the test cohort

\begin{tabular}{|c|c|c|c|c|c|c|}
\hline Periostin & Periostin stromal & Periostin epithelial & pT-status & Gleason sum & Age & Residual tumour \\
\hline \multicolumn{7}{|l|}{ Periostin epithelial } \\
\hline CC & & 0.162 & 0.057 & 0.162 & -0.108 & -0.020 \\
\hline p-value & & 0.003 & 0.307 & 0.003 & 0.053 & 0.720 \\
\hline Number of cases & & 325 & 325 & 325 & 325 & 319 \\
\hline \multicolumn{7}{|l|}{ Periostin epithelial } \\
\hline CC & 0.162 & & 0.110 & 0.191 & -0.056 & -0.027 \\
\hline p-value & 0.003 & & 0.047 & 0.001 & 0.313 & 0.626 \\
\hline Number of cases & 325 & & 325 & 325 & 325 & 319 \\
\hline
\end{tabular}

$\mathrm{CC}=$ Correlation coefficient 

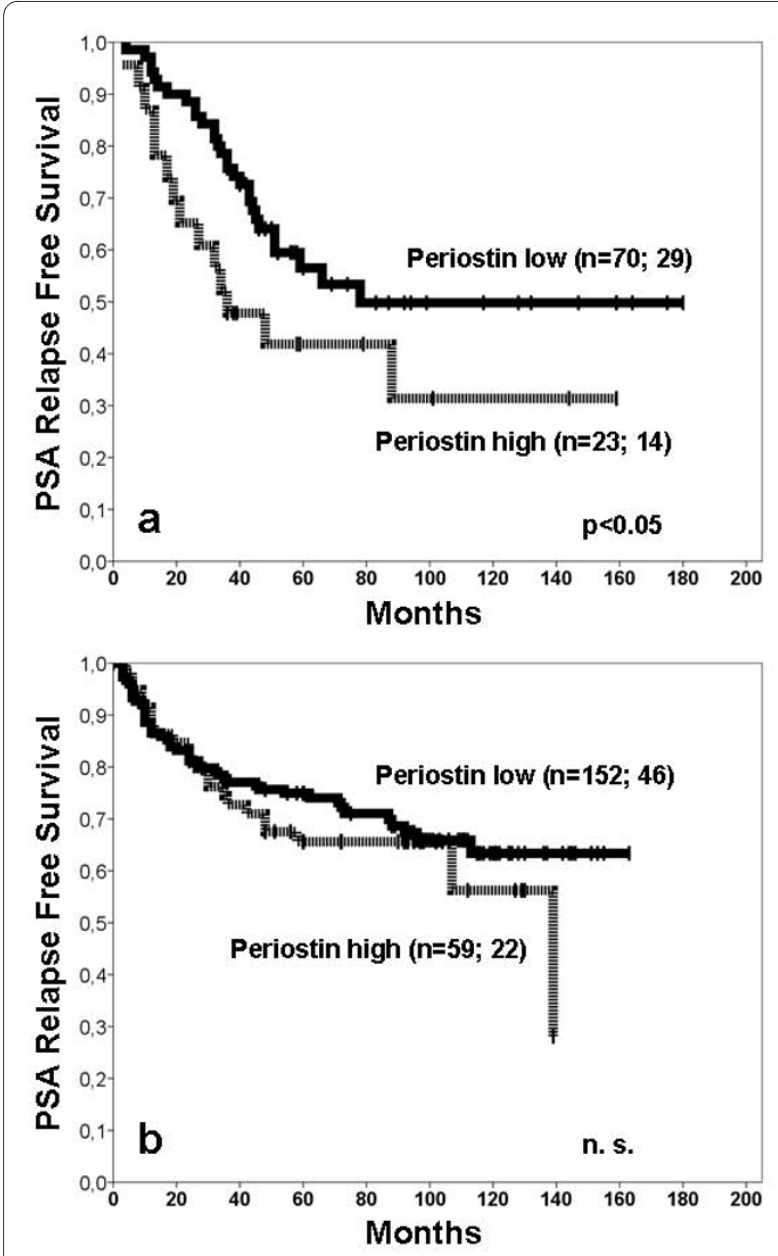

Figure 2 PSA relapse free survival for periostin in training and test cohort. a) In the training cohort higher stromal periostin expression was a significant prognosticator for shortened PSA relapse free survival ( $p=0.045$ ). The periostin low group consisted of 70 patients of which 29 had a PSA relapse. In the periostin high group 14 of the 23 patients had a PSA relapse. b) In the test cohort the curve of those patients with higher stromal periostin expression remained slightly below that of the patients with lower stromal periostin expression ( $p=$ 0.373 ). In the test cohort the periostin low group consisted of $152 \mathrm{pa}-$ tients. Forty-six patients had a PSA relapse (periostin high group: 22 of the 59 patients with PSA relapse).

There are several reports on involvement of other EMT markers eg. platelet-derived growth factor-D, hypoxiainducible factor- $1 \alpha$ and zinc finger enhancer binding protein 1 in prostate cancer [37-40]. Meanwhile, periostin has been found up-regulated in several tumour entities, either in the stroma, the epithelial cells or in the serum $[17,26,27,30,41,42]$. In most of these tumour entities, periostin has been associated with more aggressive tumour characteristics, which is perfectly in line with our findings in prostate cancer. Apart from EMT, periostin is related to other stromal re-modeling and repair processes such as wound healing or formation of heart valves in embryogenesis. It is not clear yet whether periostin upregulation reflects only the stroma re-modeling process per se or whether it is actively induced by the tumour cells themselves. The presence of both mRNA and protein in the cytoplasm of tumour cells favours an active or signal transducting role of periostin, respectively. Further functional studies are needed to shed light on the mechanism of periostin up-regulation in prostate cancer.

In our test cohort we could not reproduce the promising results concerning the prognostic value of periostin deduced from the training cohort. A possible explanation is most likely the selection of the training cohort with a very high number of cases with PSA relapse (46\%) whereas the consecutive cases of the test cohort show usual relapse rates $(21 \%)$. The selection of the training cohort was done to identify biomarker for PSA relapse. It is not uncommon to see that prognostic significances are better in trainings cohorts than in tests cohorts. The differing results for relapse free survival of both cohorts are therefore not too surprising for us, also taking into account that the composition of the cohorts is so different. However, this also demonstrates that the prognostic value of periostin is limited in comparison to well established conventional prognosticators of prostate cancer and other potentially prognostic molecular markers [36,43]. More important than a prognostic value of periostin might be its use as a therapeutic target. Kudo et $a l$. and Castranovo et al. have recently evaluated its therapeutic potential [41,44]. In a chemical proteomics approach, periostin was found accessible by the blood stream, which is an important factor for effective drugability $[41,44]$. It has been concluded that its expression characteristics and cancer specific up-regulation make periostin a promising target for ligand-based tumour targeting strategies. Considering its high expression in both stroma and tumour cells, this might be an auspicious option for advanced prostate cancer. Also, the diagnostic serological value of periostin might be worth looking at.

\section{Conclusions}

This immunohistochemical study describes the periostin protein expression pattern in prostate cancer and benign prostate tissue in a large patient cohort. Its upregulation in primary, metastatic and hormone resistant prostate cancers was related to a more aggressive and advanced tumour biology. These expression characteristics and its proposed drugability make periostin a promising target for an individualized prostate cancer therapy. 
Table 4: PSA relapse free survival in dependence of stromal and epithelial periostin expression and clinico-pathological parameters in the test cohort

\begin{tabular}{|c|c|c|c|c|}
\hline Characteristic & No. of cases & No. of events & 3-year PSA relapse rate $( \pm \mathrm{SE})$ in $\%$ & p-values \\
\hline Periostin stromal & & & & 0.373 \\
\hline low & 152 & 46 & $77.1 \pm 3.5$ & \\
\hline high & 59 & 22 & $72.7 \pm 5.8$ & \\
\hline Periostin epithelial & & & & 0.722 \\
\hline low & 133 & 41 & $77.7 \pm 3.6$ & \\
\hline high & 78 & 27 & $72.6 \pm 5.1$ & \\
\hline Age & & & & 0.514 \\
\hline$\leq 64$ years & 108 & 33 & $79.2 \pm 4.0$ & \\
\hline$>64$ years & 103 & 35 & $74.3 \pm 4.3$ & \\
\hline pT status & & & & $<0.001$ \\
\hline $\mathrm{pT} 1 / 2$ & 153 & 37 & $84.2 \pm 3.0$ & \\
\hline $\mathrm{pT} 3 / 4$ & 58 & 31 & $56.4 \pm 6.7$ & \\
\hline Gleason score & & & & $<0.001$ \\
\hline $3-6$ & 46 & 4 & $93.2 \pm 3.8$ & \\
\hline 7 & 131 & 44 & $76.0 \pm 3.8$ & \\
\hline $8-10$ & 34 & 20 & $52.0 \pm 8.7$ & \\
\hline Residual tumoura & & & & $<0.001$ \\
\hline RO & 151 & 34 & $83.8 \pm 3.0$ & \\
\hline $\mathrm{R} 1$ & 59 & 33 & $60.4 \pm 6.4$ & \\
\hline
\end{tabular}

aOne case was $\mathrm{Rx}$.

\section{Competing interests}

The authors declare that they have no competing interests.

\section{Authors' contributions}

$H M, A S, G K$ and VT designed the study, participated in the statistical analysis and drafted the manuscript. FRF and JG participated in the design of the study and performed the statistical analysis. PJW, PS, TH, HHS and HM designed the "Zurich" tissue microarray. GK, FRF, KJ and CS designed the "Berlin" tissue micro array. HHS, PJW, AM and MOR participated in collecting clinical data for the "Zurich" cohort. HM, GK, AS conceived the study, participated in its design and coordination and helped to draft the manuscript. All authors read and approved the final manuscript.

\section{Acknowledgements}

We thank Silvia Behnke, Britta Beyer and Martina Storz for excellent technical assistance. For financial support, we thank the Ludwig Institute. We are also grateful for the grant of the Sonnenfeld Stiftung to GK, which financed the Tis- sue Micro Arrayer (Berlin cohort). This work was supported by a grant from the Fondation Nuovo-Soldati to VT.

\section{Author Details}

IInstitute for Surgical Pathology, University Hospital Zurich, Zurich, Switzerland , 2Department of Urology, University Hospital Zurich, Zurich, Switzerland, ${ }^{3}$ Department of Urology, Charité - Universitätsmedizin, Berlin, Germany and 4Berlin Institute for Urologic Research, Charité - Universitätsmedizin, Berlin, Germany

Received: 18 September 2009 Accepted: 9 June 2010

Published: 9 June 2010

\section{References}

1. Takeshita S, Kikuno R, Tezuka K, Amann E: Osteoblast-specific factor 2: cloning of a putative bone adhesion protein with homology with the insect protein fasciclin I. Biochem J 1993, 294(Pt 1):271-278. 
2. Horiuchi K, Amizuka N, Takeshita S, Takamatsu H, Katsuura M, Ozawa H Toyama Y, Bonewald LF, Kudo A: Identification and characterization of a novel protein, periostin, with restricted expression to periosteum and periodontal ligament and increased expression by transforming growth factor beta. J Bone Miner Res 1999, 14(7):1239-1249.

3. Oshima A, Tanabe H, Yan T, Lowe GN, Glackin CA, Kudo A: A novel mechanism for the regulation of osteoblast differentiation: transcription of periostin, a member of the fasciclin I family, is regulated by the bHLH transcription factor, twist. Journal of cellular biochemistry 2002, 86(4):792-804.

4. Kruzynska-Frejtag A, Machnicki M, Rogers R, Markwald RR, Conway SJ: Periostin (an osteoblast-specific factor) is expressed within the embryonic mouse heart during valve formation. Mechanisms of development 2001, 103(1-2):183-188.

5. Kruzynska-Frejtag A, Wang J, Maeda M, Rogers R, Krug E, Hoffman S, Markwald RR, Conway SJ: Periostin is expressed within the developing teeth at the sites of epithelial-mesenchymal interaction. Dev Dyn 2004, 229(4):857-868

6. Wilde J, Yokozeki M, Terai K, Kudo A, Moriyama K: The divergent expression of periostin mRNA in the periodontal ligament during experimental tooth movement. Cell and tissue research 2003, 312(3):345-351.

7. Nakazawa T, Nakajima A, Seki N, Okawa A, Kato M, Moriya H, Amizuka N, Einhorn TA, Yamazaki M: Gene expression of periostin in the early stage of fracture healing detected by cDNA microarray analysis. J Orthop Res 2004, 22(3):520-525.

8. Li P, Oparil S, Feng W, Chen YF: Hypoxia-responsive growth factors upregulate periostin and osteopontin expression via distinct signaling pathways in rat pulmonary arterial smooth muscle cells. J App/ Physiol 2004, 97(4):1550-1558. discussion 1549

9. Shao R, Bao S, Bai X, Blanchette C, Anderson RM, Dang T, Gishizky ML, Marks JR, Wang XF: Acquired expression of periostin by human breast cancers promotes tumor angiogenesis through up-regulation of vascular endothelial growth factor receptor 2 expression. Molecular and cellular biology 2004, 24(9):3992-4003.

10. Lindner V, Wang Q, Conley BA, Friesel RE, Vary CP: Vascular injury induces expression of periostin: implications for vascular cell differentiation and migration. Arterioscler Thromb Vasc Biol 2005, 25(1):77-83.

11. Shimazaki M, Nakamura K, Kii I, Kashima T, Amizuka N, Li M, Saito M, Fukuda K, Nishiyama T, Kitajima S, et al: Periostin is essential for cardiac healing after acute myocardial infarction. J Exp Med 2008, 205(2):295-303.

12. Litvin J, Zhu S, Norris R, Markwald R: Periostin family of proteins: therapeutic targets for heart disease. Anat Rec A Discov Mol Cell Evol Biol 2005, 287(2):1205-1212

13. Bao S, Ouyang G, Bai X, Huang Z, Ma C, Liu M, Shao R, Anderson RM, Rich JN, Wang XF: Periostin potently promotes metastatic growth of colon cancer by augmenting cell survival via the Akt/PKB pathway. Cancer Cell 2004, 5(4):329-339.

14. Yan W, Shao R: Transduction of a mesenchyme-specific gene periostin into 293 T cells induces cell invasive activity through epithelialmesenchymal transformation. J Biol Chem 2006, 281(28):19700-19708.

15. Gillan L, Matei D, Fishman DA, Gerbin CS, Karlan BY, Chang DD: Periostin secreted by epithelial ovarian carcinoma is a ligand for alpha(V)beta(3) and alpha(V)beta(5) integrins and promotes cell motility. Cancer Res 2002, 62(18):5358-5364

16. Baril P, Gangeswaran R, Mahon PC, Caulee K, Kocher HM, Harada T, Zhu M, Kalthoff H, Crnogorac-Jurcevic T, Lemoine NR: Periostin promotes invasiveness and resistance of pancreatic cancer cells to hypoxiainduced cell death: role of the beta4 integrin and the PI3k pathway. Oncogene 2007, 26(14):2082-2094.

17. Erkan M, Kleeff J, Gorbachevski A, Reiser C, Mitkus T, Esposito I, Giese T, Buchler MW, Giese NA, Friess H: Periostin creates a tumor-supportive microenvironment in the pancreas by sustaining fibrogenic stellate cell activity. Gastroenterology 2007, 132(4):1447-1464.

18. Fluge $O$, Bruland $O$, Akslen LA, Lillehaug JR, Varhaug JE: Gene expression in poorly differentiated papillary thyroid arcinomas. Thyroid 2006, 16(2):161-175

19. Forsti A, Jin Q, Altieri A, Johansson R, Wagner K, Enquist K, Grzybowska E Pamula J, Pekala W, Hallmans G, et al.: Polymorphisms in the KDR and POSTN genes: association with breast cancer susceptibility and prognosis. Breast cancer research and treatment 2007, 101(1):83-93.
20. Fukushima N, Kikuchi Y, Nishiyama T, Kudo A, Fukayama M: Periostin deposition in the stroma of invasive and intraductal neoplasms of the pancreas. Mod Pathol 2008, 21(8):1044-53.

21. Gonzalez HE, Gujrati M, Frederick M, Henderson Y, Arumugam J, Spring PW, Mitsudo K, Kim HW, Clayman GL: Identification of 9 genes differentially expressed in head and neck squamous cell carcinoma. Archives of otolaryngology--head \& neck surgery 2003, 129(7):754-759.

22. Kanno A, Satoh K, Masamune A, Hirota M, Kimura K, Umino J, Hamada S, Satoh A, Egawa S, Motoi F, et al:: Periostin, secreted from stromal cells, has biphasic effect on cell migration and correlates with the epithelial to mesenchymal transition of human pancreatic cancer cells. International journal of cancer 2008, 122(12):2707-2718.

23. Kikuchi Y, Kashima TG, Nishiyama T, Shimazu K, Morishita Y, Shimazaki M, Kii I, Horie H, Nagai H, Kudo A, et al.: Periostin Is Expressed in Pericryptal Fibroblasts and Cancer-associated Fibroblasts in the Colon. $J$ Histochem Cytochem 2008, 56(8):753-764.

24. Kudo Y, Ogawa I, Kitajima S, Kitagawa M, Kawai H, Gaffney PM, Miyauchi $M$, Takata T: Periostin promotes invasion and anchorage-independent growth in the metastatic process of head and neck cancer. Cancer research 2006, 66(14):6928-6935.

25. Li JS, Sun GW, Wei XY, Tang WH: Expression of periostin and its clinicopathological relevance in gastric cancer. World J Gastroenterol 2007, 13(39):5261-5266.

26. Puglisi F, Puppin C, Pegolo E, Andreetta C, Pascoletti G, D'Aurizio F, Pandolfi M, Fasola G, Piga A, Damante G, et al.: Expression of periostin in human breast cancer. Journal of clinical pathology 2008, 61(4):494-498.

27. Puppin C, Fabbro D, Dima M, Di Loreto C, Puxeddu E, Filetti S, Russo D, Damante $G$ : High periostin expression correlates with aggressiveness in papillary thyroid carcinomas. The Journal of endocrinology 2008, 197(2):401-408

28. Sasaki H, Dai M, Auclair D, Fukai I, Kiriyama M, Yamakawa Y, Fujii Y, Chen LB: Serum level of the periostin, a homologue of an insect cell adhesion molecule, as a prognostic marker in nonsmall cell lung carcinomas. Cancer 2001, 92(4):843-848.

29. Sasaki H, Lo KM, Chen LB, Auclair D, Nakashima Y, Moriyama S, Fukai I, Tam C, Loda M, Fujii Y: Expression of Periostin, homologous with an insect cell adhesion molecule, as a prognostic marker in non-small cell lung cancers. Jpn J Cancer Res 2001, 92(8):869-873.

30. Sasaki H, Sato Y, Kondo S, Fukai I, Kiriyama M, Yamakawa Y, Fuji Y Expression of the periostin mRNA level in neuroblastoma. Journal of pediatric surgery 2002, 37(9):1293-1297.

31. Siriwardena BS, Kudo Y, Ogawa I, Kitagawa M, Kitajima S, Hatano H, Tilakaratne WM, Miyauchi M, Takata T: Periostin is frequently overexpressed and enhances invasion and angiogenesis in oral cancer. British journal of cancer 2006, 95(10):1396-1403.

32. Soltermann A, Tischler V, Arbogast S, Braun J, Probst-Hensch N, Weder W, Moch $\mathrm{H}$, Kristiansen G: Prognostic significance of epithelialmesenchymal and mesenchymal-epithelial transition protein expression in non-small cell lung cancer. Clin Cancer Res 2008 14(22):7430-7437.

33. Riener $\mathrm{MO}$, Fritzsche FR, Soll C, Pestalozzi BC, Probst-Hensch N, Clavien PA, Jochum W, Soltermann A, Moch H, Kristiansen G: Expression of the Extracellular Matrix Protein Periostin in Liver Tumors and Bile Duct Carcinomas. Histopathology 2010.

34. Soltermann A, Ossola R, Kilgus-Hawelski S, von Eckardstein A, Suter T, Aebersold R, Moch $\mathrm{H}$ : N-glycoprotein profiling of lung adenocarcinoma pleural effusions by shotgun proteomics. Cancer 2008, 114(2):124-133.

35. Tsunoda T, Furusato B, Takashima Y, Ravulapalli S, Dobi A, Srivastava S, McLeod DG, Sesterhenn IA, Ornstein DK, Shirasawa S: The increased expression of periostin during early stages of prostate cancer and advanced stages of cancer stroma. Prostate 2009, 69(13):1398-403.

36. Weichert W, Roske A, Gekeler V, Beckers T, Stephan C, Jung K, Fritzsche FR, Niesporek S, Denkert C, Dietel M, et al:: Histone deacetylases 1, 2 and 3 are highly expressed in prostate cancer and HDAC2 expression is associated with shorter PSA relapse time after radical prostatectomy. Br J Cancer 2008, 98(3):604-610.

37. Kong D, Wang Z, Sarkar SH, Li Y, Banerjee S, Saliganan A, Kim HR, Cher ML, Sarkar FH: Platelet-derived growth factor-D overexpression contributes to epithelial-mesenchymal transition of $\mathrm{PC} 3$ prostate cancer cells. Stem Cells 2008, 26(6):1425-1435.

38. Hugo H, Ackland ML, Blick T, Lawrence MG, Clements JA, Williams ED, Thompson EW: Epithelial--mesenchymal and mesenchymal--epithelial transitions in carcinoma progression. J Cell Physio/ 2007, 213(2):374-383. 
39. Jiang YG, Luo Y, He DL, Li X, Zhang LL, Peng T, Li MC, Lin YH: Role of Wnt/ beta-catenin signaling pathway in epithelial-mesenchymal transition of human prostate cancer induced by hypoxia-inducible factor-1alpha. Int J Urol 2007, 14(11):1034-1039.

40. Graham TR, Zhau HE, Odero-Marah VA, Osunkoya AO, Kimbro KS, Tighiouart M, LiU T, Simons JW, O'Regan RM: Insulin-like growth factor-Idependent up-regulation of ZEB1 drives epithelial-to-mesenchymal transition in human prostate cancer cells. Cancer Res 2008, 68(7):2479-2488.

41. Castronovo V, Waltregny D, Kischel P, Roesli C, Elia G, Rybak JN, Neri D: A chemical proteomics approach for the identification of accessible antigens expressed in human kidney cancer. Mol Cell Proteomics 2006, 5(11):2083-2091.

42. Sasaki H, Dai M, Auclair D, Kaji M, Fukai I, Kiriyama M, Yamakawa Y, Fujii Y, Chen LB: Serum level of the periostin, a homologue of an insect cell adhesion molecule, in thymoma patients. Cancer letters 2001, 172(1):37-42.

43. Fritzsche FR, Jung M, Tolle A, Wild P, Hartmann A, Wassermann K, Rabien A, Lein M, Dietel M, Pilarsky C, et al: ADAM9 expression is a significant and independent prognostic marker of PSA relapse in prostate cancer. Eur Urol 2008, 54(5):1097-1106.

44. Kudo Y, Siriwardena BS, Hatano H, Ogawa I, Takata T: Periostin: novel diagnostic and therapeutic target for cancer. Histol Histopathol 2007, 22(10):1167-1174.

\section{Pre-publication history}

The pre-publication history for this paper can be accessed here: http://www.biomedcentral.com/1471-2407/10/273/prepub

doi: 10.1186/1471-2407-10-273

Cite this article as: Tischler et al., Periostin is up-regulated in high grade and high stage prostate cancer BMC Cancer 2010, 10:273

Submit your next manuscript to BioMed Central and take full advantage of:

- Convenient online submission

- Thorough peer review

- No space constraints or color figure charges

- Immediate publication on acceptance

- Inclusion in PubMed, CAS, Scopus and Google Scholar

- Research which is freely available for redistribution

Submit your manuscript at www.biomedcentral.com/submit
Ciomed Central 